\title{
Repair compositions for restoration of operated reinforced concrete structures
}

\author{
Elena Shlyakhova ${ }^{1}$, Irina Serebryanaya $^{1,{ }^{*}}$, Inna Egorochkina ${ }^{1}$, Andrey Matrosov ${ }^{1}$, Maxim \\ Odinets $^{1}$, and Michael Knyazhichenko ${ }^{1}$ \\ ${ }^{1}$ Don State Technical University, 1, Gagarin Sq., 344003, Rostov-on-Don, Russia
}

\begin{abstract}
Power transmission lines (PTL) are strategic objects, the reliability of which depends on the life support of the country. Most of the currently operated power transmission lines were put into operation in the twentieth century, and by now there is a problem of assessing their technical condition, repairing them, if necessary, and maintaining them in a working condition. Defects that appear during the operation of reinforced concrete elements of power transmission lines have different localization and degree of manifestation, but typical is the destruction of the surface layer of concrete with exposure of rebar, more often at the base of the power transmission line. The aim of the work is to select the optimal composition of the repair mixture based on non-shrinking and expanding cements, ensuring reliable adhesion of the repair compounds to the concrete of the structure, which will restore the bearing and operational characteristics in the repaired reinforced concrete elements of the power transmission line at the design level.
\end{abstract}

\section{Introduction}

The considerable experience accumulated at present in the operation of power transmission lines (hereinafter referred to as PTL) both in our country and around the world makes it possible to judge the practical operational reliability of all elements of power transmission lines.

Most of the currently operated PTL were put into operation in the twentieth century, and over the past few decades, the deterioration of high voltage power grids, according to most experts, has increased to $40 \%$. Given the high degree of deterioration of existing facilities, to maintain them in working condition, it is necessary to periodically carry out diagnostic measures [1], as well as repair work.

The search for new solutions for the effective restoration of the technical condition of PTL and the problem of timely diagnosis of damage are the urgent tasks of the modern electric power industry [2,3].

Currently known measures to restore the operational reliability of reinforced concrete elements of PTL in most cases require significant costs of materials and special repair compositions. These activities are very time consuming. Their implementation requires special equipment and appropriately trained personnel. In addition, the complexity is

*Corresponding author: silveririna@mail.ru 
caused by the diversity of the raw material base for the manufacture of repair compounds in different climatic regions of the country, and often the low quality of the raw materials used.

The relevance of this work is due to the fact that PTL, which are a complex technological and structural complex containing a significant number of components, are strategically important facilities in any country and the country's life support depends on their reliability.

We have carried out experimental studies on the development of effective repair compositions for the restoration of operated reinforced concrete structures of PTL. These structural elements perform the main bearing function as part of the PTL and the long-term and trouble-free operation of the entire power transmission line will depend on their technical condition. The destruction of PTL supports can lead to early failure of the entire line, which will require its partial or complete dismantling.

Defects that appear during the operation of reinforced concrete elements of power lines can have different localization and degree of manifestation. Outwardly, this can manifest itself in the form of various destructions (Figure 1).

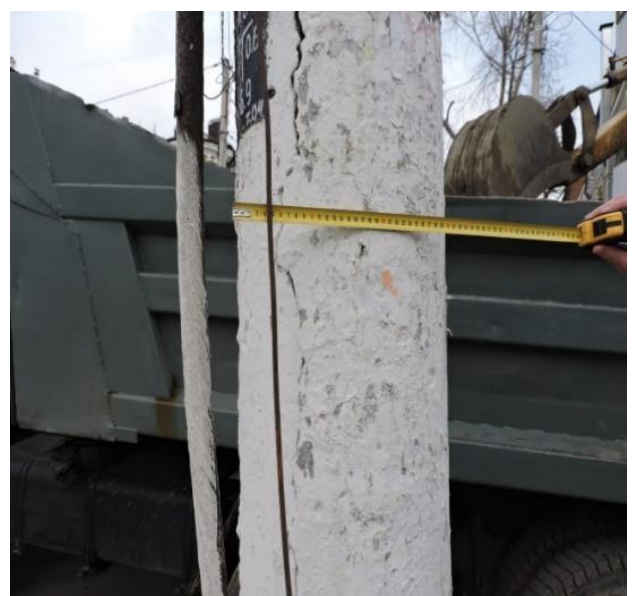

(a)

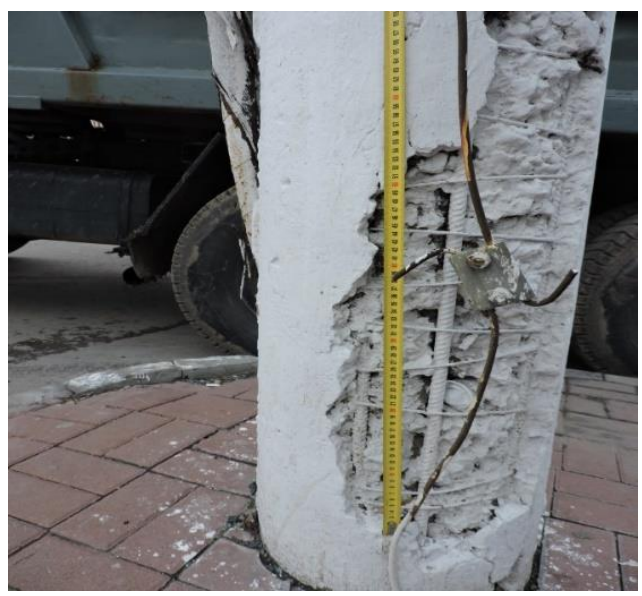

(b)

Fig. 1. (a) solid-section PTL, (b) centrifuged PTL.

An alternative to replacing individual structural elements of PTL or even entire sections can be the restoration of reinforced concrete structures as a result of repair work. The loadbearing and operational characteristics in the restored reinforced concrete elements of the PTL can be maintained at the level of design indicators, provided that the repair restoring compositions are reliably adhered to the restored structures.

The experience gained to date in the use of conventional mortars or sandy concretes based on Portland cement for grouting precast concrete structures indicates that such compositions do not sufficiently provide the required solidity of structures. This is mainly due to the fact that such compositions undergo shrinkage during setting and hardening. In this regard, the problem of creating expandable and non-shrinking cements for the designated purposes is urgent.

In the 70 s of the last century [4] a method was developed for preparing expandable waterproof cements, which are characterized by the fact that they are subject to shrinkage during hydraulic hardening. The cement used in this case has a high setting rate and the achievement of the required degree of strength. The used binder is obtained from a mixture of aluminate cement, gypsum dihydrate $(\mathrm{CaSO} 42 \mathrm{H} 2 \mathrm{O})$ and tetra calcium aluminate, which are finely ground in a ball mill. The tetracalcium aluminate is obtained by autoclaving a 
mixture of alumina cement and lime in a mass ratio of $1: 1$ with a water-solid ratio W/S of 0.30 . Next, the resulting product is dried and milled. The advantage of the developed expanding cement is that the degree of its expansion can be regulated within a fairly wide range by changing the ratio between the components.

It should be noted that the formation of the hydrosulfoaluminate framework when cement is mixed with water occurs during the induction period of the structure formation of the cement stone, when coagulation processes still prevail in it. Therefore, expansion occurs without breaking the continuity of the structure, which ensures the achievement of the required strength and density of the resulting material.

The disadvantage of this cement is the complexity of storage due to its high hygroscopicity, as well as technological difficulties due to the rapid setting. In addition, the negative properties of this cement include the fact that the degree of expansion depends on the temperature and humidity conditions of hardening, as well as a reduced, in comparison with Portland cement, ability to protect steel reinforcement of reinforced concrete.

The widespread use of expanding composites based on aluminate cement is constrained by its high cost, as well as technological difficulties during construction work. These difficulties are caused by the shortened setting time and the high sensitivity of the cement in relation to changes in the temperature and humidity conditions of hardening.

The characteristic disadvantages of expanding cements based on alumina highaluminate components are largely overcome by using expanding composites based on Portland cement [5-8].

When developing expanding compositions based on Portland cement, the principle of compensated expansion was put forward and substantiated [4, 5]. According to this principle, in such formulations, expansion occurs mainly due to the inclusion of a small amount of aluminum powder additive in the mixture. The latter enters into chemical interaction with the resulting hydration products of Portland cement, as a result of which many small bubbles of hydrogen gas are formed in the mixture. At the same time, the external volume of the system increases, ensuring its expansion. To prevent a decrease in the strength properties and water resistance of the resulting expanding composite, in addition to aluminum powder, chemical additives are additionally introduced into the mixture. These additives include calcium chloride, sulphate aluminate and a surfactant sulphite-alcoholic mash SSB (currently not produced by the pulp and paper industry).

Thus, expanding Portland cement contains a four-component complex additive with the following ratio of components in percent: by weight of the cement consumption - 0.01 aluminum.powder; 2.0 aluminum sulfate; 2.0 calcium chloride; 0.15 sulfite-alcohol brew SSB. These components are introduced into the concrete mix together with mixing water. The presence of the SSB additive ensures uniform distribution of finely dispersed aluminum powder in a concrete or mortar mixture without first removing the paraffin film from its particles. The positive effect of the SSB additive is that the calcium lignosulfonate included in its composition is deposited on the surface of the aluminum powder particles, which contributes to their uniform distribution in the form of a suspension in the liquid phase. That is why, if usually a system of interconnected capillaries and pores is formed in the cement stone, then in this case, the smallest closed gas pores are formed in the cement stone, evenly distributed throughout the volume of the cement stone.

Aluminum sulfate and calcium chloride, which are part of the expanding additive, enter into chemical interaction with hydrating cement, which contributes to the partial filling of the above-described gas pores with crystalline neoplasms. These components of the expanding additive provide clogging (filling) of the pores of the cement stone with complex salts crystallizing in them, such as hydrosulfoaluminates and calcium hydrochloroaluminates. This forms a very dense cement stone, in which the smallest partially sealed pores are evenly distributed. As a result, the strength indicators, water 
resistance and frost resistance of the resulting material are significantly increased, which is confirmed by comprehensive studies [9-11].

At the same time, along with all the advantages of the considered expanding binders based on Portland cement, it should be noted their certain disadvantage, which consists in the technological complexity of dosing and the practical application of a four-component expanding complex additive. At the same time, the SSB plasticizer has already been discontinued.

\section{Goals and objectives}

The purpose of this work is to study the possibility of creating effective expanding compositions intended for carrying out repair and restoration activities on the existing reinforced concrete poles of PTL, based on Portland cement, local fine sand contaminated with impurities of dusty and clay particles, and components of a complex expanding additive available in regional conditions.

When setting the task the following considerations were taken into account. In all known expanding cements, both based on alumina cement and based on Portland cement, neoplasms such as calcium hydrosulfoaluminate play a decisive role. Calcium hydrosulfoaluminate can influence the processes of structure formation of cement stone in two ways, depending on the time factor of its formation in the system. One of the first to come to this conclusion was Lyafum, who formulated the fundamental position that in the process of direct interaction of substances in the solid phase, dangerous deformations can appear in the hardening cement stone. This is due to the fact that when new formations are crystallized on the surfaces of interconnected structural particles, the structure of the cement stone as a whole is damaged. The reaction of formation of calcium hydrosulfoaluminate in the liquid phase proceeds in a different way. In this case, new formations crystallize in the free gaps of the structure, leading to its compaction and hardening.

When hardening ordinary Portland cement, there are always the above conditions for the formation of calcium hydrosulfoaluminate. In particular, in the process of hydration of the predominant mass content in the composition of the clinker mineral $\mathrm{C} 3 \mathrm{~S}$ (tricalcium silicate), lime is inevitably formed in the form of portlandite $\mathrm{Ca}(\mathrm{OH}) 2$. In the production of cement, gypsum is compulsorily added, which is a regulator of the cement setting time.

To achieve the expansion effect of the resulting Portland cement stone, it is necessary to ensure the necessary increase in the amount of calcium hydrosulfoaluminate formed in the earliest period of structure formation.

It is possible to purposefully regulate the composition of Portland cement clinker, increasing the content of such clinker minerals as tricalcium aluminate $\mathrm{C} 3 \mathrm{~A}$, or tricalcium silicate $\mathrm{C} 3 \mathrm{~S}$, involved in the formation of calcium hydrosulfoaluminate, only when cement is manufactured at the factory. Naturally, it is not possible to control the kinetics of the formation of calcium hydrosulfoaluminate in this way when making mixtures for repair and restoration works in relation to the poles of power lines.

The content of gypsum in cement can be increased by adding it while mixing the repair mixture, however, it is practically difficult to distribute it in cement in the field without having additional appropriate mixing equipment, which is equipped with conventional stationary concrete mixing units.

It is known that it is possible to increase the content of gypsum with a uniform distribution in the hardening system under normal conditions by adding easily dissolving sulfate-containing substances to the mixing water, for example, Glauber's salt Na2SO4 (sodium sulfate $\mathrm{CH}$ ). 


\section{Experimental part}

The use of aluminum powder as an expanding component in the composition of a complex additive is associated with the complexity of its dosage and uniform distribution in the mixture. This is explained by the fact that finely ground particles of metallic aluminum in the process of its production are covered with a paraffin protective film in order to avoid its oxidation and spontaneous combustion. This paraffin coating prevents wetting of the aluminum powder particles, which complicates its uniform distribution in the mixing water volume when preparing mixtures. In order to exclude this phenomenon, the aluminum powder is released from the paraffin film by introducing surfactants into the mixing water.

In this work, we studied the possibility of using the ST 2.1 superplasticizer additive for this purpose, which is introduced into the mixture in a ratio with aluminum powder by weight $1: 1$.

As part of the expanding additive, it was decided to use sodium sulphate $\mathrm{CH}$ as a sulphate-containing component. To obtain an expanding composition based on Portland cement, the content of the gas-forming additive aluminum powder in the complex developed additive was assumed to be equal to $0.01 \%$ of the weight of Portland cement.

In order to establish a rational amount of sodium sulfate $\mathrm{CH}$ in the composition of the expanding additive developed for carrying out repair and restoration work of power transmission line racks, a special calculation was performed. The calculated amount of the addition of sodium sulfate in the composition of the expanding additive is determined from the condition that the resulting calcium hydrosulfoaluminate compensates for the contractional shrinkage of the hardening Portland cement stone. At the same time, clogging of the so-called "open" capillaries and pores in its structure must be ensured. The quantitative ratios of both the reagents and the products of the formation reaction in the solidifying system of calcium hydrosulfoaluminate after the completion of the corresponding chemical reaction were determined from the conditions of the process.

Calculations have shown that the content of sodium sulfate in the composition of the developed expanding additive should be in the range of $1.5-2.5 \%$ of the cement mass. As a result of the analysis, for further experimental studies of expanding compositions based on local substandard raw materials, it seemed expedient to use the proposed expanding additive in the composition of repair mixtures, including $0.01 \%$ by weight of cement additive ST 2.1, aluminum powder and $1.5-2,5 \%$ sodium sulfate.

When studying the effect of the formulation on the construction and technical properties of sandy concrete, used as a repair material for the restoration of PTL supports, a set of indicators was adopted as the optimized response functions:

- from the condition of ensuring the equal strength of concrete materials for power transmission line supports and their restored sections, the requirement was formulated to achieve a branded strength of at least $30 \mathrm{MPa}$ (class B22.5 in strength);

- a generalized criterion for the resistance of concrete under the typical operating conditions of power transmission towers cyclic aggressive environmental influences, such as alternate humidification and drying, freezing and thawing, etc., in experimental studies, the value of the strength characteristic of the crack resistance of concrete, determined in accordance with the requirements of GOST 29167, was adopted. The strength characteristic of the crack resistance of concrete, or the so-called fracture toughness under static loading, is estimated under the conditions of non-equilibrium mechanical tests by the value of the critical stress coefficient $\mathrm{K}^{*} \mathrm{c}$.

To obtain comparative data on the Samara sand of the Rostov region and Portland cement of Sebryakovcement JSC PC500 D0, cement-sand mixtures of the composition cement: sand in a ratio of $1: 2$ at $\mathrm{W} / \mathrm{C}=0.51$ were prepared without an expanding additive and in combination with the introduction of the proposed complex expansion additive. 
From the mixtures obtained, specimens-bars of standard sizes $4 \times 4 \times 16 \mathrm{~cm}$ were molded, which at the age of 28 days of normal hardening were tested for crack resistance. Features of the technology of manufacturing full-scale samples are presented in [12].

Table 1. Influence of expansion additive on crack resistance of sandy concrete.

\begin{tabular}{|l|c|c|c|}
\hline \multicolumn{1}{|c|}{ Repair mixture type } & $\begin{array}{c}\text { Initial cut relative } \\
\text { depth } \mathbf{a}_{\mathbf{0}} \mathbf{~ m}\end{array}$ & $\begin{array}{c}\text { Loading } \\
\text { F. MH }\end{array}$ & $\begin{array}{c}\text { Crack } \\
\text { resistance } \\
\text { coefficient } \mathbf{K}_{\mathbf{c}}^{*}\end{array}$ \\
\hline $\begin{array}{l}\text { Mixture on sand with 4.2\% dust and } \\
\text { clay impurities. additive ST 2.1 2.5\% }\end{array}$ & 0.011 & 4.37 & $0.42 / 100 \%$ \\
\hline $\begin{array}{l}\text { Mixture with additive ST 2.1 2.5\% in } \\
\text { combination with the addition of an } \\
\text { expanding additive containing 2.4\% } \\
\text { CH and 0.01\% Al into the mixture }\end{array}$ & 0.013 & 4.49 & $0.49 / 117 \%$ \\
\hline
\end{tabular}

\section{Conclusion}

The tests showed that the proposed expanding addition of compositions for repair and restoration work of power transmission line supports provides not only an increase in the strength of the resulting material, but also increases its crack resistance by $17 \%$ and, thereby, contributes to an increase in the degree of durability and reliability of the restored structure (Table 1).

Thus, it has been experimentally established that the developed expanding complex additive significantly increases the crack resistance and strength of sandy concrete and improves its structure. This may be the basis for using the proposed solutions when performing work on the repair of PTL.

Assessment of the quality of repair and restoration work, carried out in accordance with the methodology outlined in [13], confirmed the high rates of adhesive adhesion of the developed four-component repair composition with the concrete of the structure of the PTL.

\section{References}

1. Yu.M. Bazhenov, Concrete Technology 3-4, 39-42 (2012)

2. L. Mailyan, S. Yaziev, L. Sabitov et al., E3S Web of Conferences 164, 02035 (2020)

3. Y.M. Bazhenov, V.T. Erofeev, V.I. Rimshin et al., Engineering Solid Mechanics 4, 219-225 (2016)

4. E.A. Shlyakhova, I.O. Egorochkina, A.V., Cherpakov, Proceedings of the 2018 Int. Conf. on Physics and Mechanics of New Materials and Their Applications (PHENMA) (Busan South Korea), 227-232 (2018)

5. A.V. Cherpakov, E.A. Shlyakhova, I.O. Egorochkina, Ya.A. Kokareva, Materials Science Forum 931, 373-378 (2018)

6. V.V. Mikhailov, Expanding and stressing cements and self-stressed reinforced concrete structures (Moscow, Stroyizdat, 1974)

7. O.P. Mchedlov-Petrosyan, I.V. Borovskaya, Cement 6, 6-8 (1983)

8. I.Ya. Kharchenko, A.P. Pustovgar, S.A. Pashkevich et al., Magazine of Civil Engineering 75(7), 161-170 (2017)

9. L. Alimov, I. Kharchenko, V. Voronin, MATEC Web of Conferences 117, 00006 (2017) 
10. G.V. Nesvetaev, M.N. Grigoryan, B.M. Yazyev, Construction and Architecture: Theory and Practice for the innovation Development 974, 413-418 (2020)

11. E.A. Shlyakhova, I.O. Egorochkina, I.A. Serebryanaya, A.A. Matrosov, Materials and Technologies in Construction and Architecture 931, 618-623 (2018)

12. I. Kharchenko, A. Panchenko, A. Kharchenko, V. Alekseev, MATEC Web of Conferences 196, 04035 (2018)

13. M.Yu. Titov, Construction Materials 2, 84-86 (2012)

14. I.A. Efremova, Concrete with Combined Aggregate Based on Portland Cement with Expansion Additives (1997)

15. I.O. Egorochkina, A.K. Khalyushev, E.M. Scherban et al., IOP Conference Series: Materials Science and Engineering 905(1), 012061 (2020)

16. A.E. Sheikin, L.M. Dobshits, SU 1558882 A1, 23.04.1990 4280741

17. A.I. Panchenko, Y.M. Bazhenov, I.Ya. Kharchenko, Durability of the concrete based on a Sulphate-Aluminate Cement (American Concrete Institute) SP 326 (2018)

18. T.A. Shcherbinina, I.A. Serebryanaya, Izvestia of the Rostov State University of Civil Engineering 2(20), 394-395 (2015)

19. I.Ya. Kharchenko, A.P. Pustovgar, S.A. Pashkevich, Yu.M. Bazhenov, A.I. Kharchenko, Magazine of Civil Engineering 7, 161-170 (2017)

20. I. Pulyaev, S. Pulyaev, Y. Bazhenov, A. Fetisova, O. Shcherbeneva, E3S Web of Conferences 97, 06026 (2019) 